\title{
Tumor PD-L1 status and CD8+ tumor-infiltrating T cells: markers of improved prognosis in oropharyngeal cancer
}

\author{
Astrid De Meulenaere ${ }^{1, *}$, Tijl Vermassen ${ }^{1}$, Sandrine Aspeslagh ${ }^{2}$, Philippe Deron ${ }^{3}$, \\ Fréderic Duprez ${ }^{4}$, Debby Laukens ${ }^{5}$, Jo Van Dorpe ${ }^{6}$, Liesbeth Ferdinande ${ }^{6, *}$ and \\ Sylvie Rottey ${ }^{1, *}$ \\ ${ }^{1}$ Department of Medical Oncology, Ghent University Hospital, 9000 Ghent, Belgium \\ ${ }^{2}$ DITEP, Gustave Roussy Cancer Centre, 94800 Villejuif, France \\ ${ }^{3}$ Department of Head, Neck and Maxillo-Facial Surgery, Ghent University Hospital, 9000 Ghent, Belgium \\ ${ }^{4}$ Department of Radiation Oncology, Ghent University Hospital, 9000 Ghent, Belgium \\ ${ }^{5}$ Department of Internal Medicine, Ghent University Hospital, 9000 Ghent, Belgium \\ ${ }^{6}$ Department of Pathology, Ghent University Hospital, 9000 Ghent, Belgium \\ *These authors are senior authors
}

Correspondence to: Astrid De Meulenaere, email: astrid.demeulenaere@ugent.be

Keywords: oropharynx, HPV, PD-L1, tumor infiltrating lymphocytes, biomarker

Received: March 06, 2017 Accepted: June 20, $2017 \quad$ Published: July 06, 2017

Copyright: De Meulenaere et al. This is an open-access article distributed under the terms of the Creative Commons Attribution License 3.0 (CC BY 3.0), which permits unrestricted use, distribution, and reproduction in any medium, provided the original author and source are credited.

\section{ABSTRACT}

Introduction: The aim of this study was to evaluate the expression of PD-L1 in oropharyngeal squamous cell carcinoma. Its relation with clinicopathological variables, tumor infiltrating lymphocytes and survival was also determined.

Results: Positive PD-L1 status for the SP142 clone related with improved overall survival in oropharyngeal squamous cell carcinoma. Tumors heavily infiltrated by tumor infiltrating lymphocytes were also linked with better outcome, and this as well for the total number of tumor infiltrating lymphocytes as for the $\mathrm{CD}^{+}$and $\mathrm{CDB}^{+}$ T cell count. A Cox proportional hazard model proved that solely infiltrating $\mathrm{CDB}^{+} \mathbf{T}$ cells exhibit a positive effect on overall survival (hazard ratio $=0.31[0.14-0.70]$; $P=0.0050$ )

Materials and Methods: Formalin-fixed, paraffin-embedded tissue from oropharyngeal tumors of 99 patients was immunohistochemically stained for PD-L1 (SP142 and 22C3 clones), CD3, CD8 and FoxP3. Expression of PD-L1, CD3, CD8, FoxP3 and HPV status were correlated with clinicopathological variables. Overall survival was determined by a log-rank (Mantel-Cox) test whereas the Cox proportional hazard model was used for multivariate analysis.

Conclusions: Our results demonstrate that $\mathrm{CD8}^{+} \mathrm{T}$ Iymphocytes constitute an independent prognostic marker in patients diagnosed with oropharyngeal squamous cell carcinoma. PD-L1 positivity for SP142, but not for $22 \mathrm{C3}$, also tends to have a positive effect on survival in oropharyngeal squamous cell carcinoma.

\section{INTRODUCTION}

Over the last decades there has been an increase in oropharyngeal squamous cell carcinoma (OSCC) which has mainly been attributed to human papillomavirus (HPV) infection [1, 2]. HPV-associated OSCC seems to be a distinct clinical entity, compared to tobacco related squamous cell carcinoma of the head and neck (SCCHN): patients (1) tend to be younger, (2) lack a history of smoking and/or alcohol abuse and (3) have a significant survival benefit [1, 3-9]. These observations have raised the possibility that some of these patients 
receive unnecessary treatment and are therefore exposed to unnecessary toxicity. Refining patient stratification by considering additional biomarkers next to HPV status may ensure appropriate therapy and therefore better survival and improved quality of life.

Programmed cell death protein 1 (PD-1) is a 50-55 $\mathrm{kDa}$ type I transmembrane receptor expressed by activated $\mathrm{T}$ and $\mathrm{B}$ cells, as well as by monocytes and dendritic cells. It has two binding partners, PD-L1 and PD-L2, each specific for various tissue types and with specific expression patterns. PD-L1 is expressed on immune cells (ICs) including T cells, dendritic cells and monocytes. In addition, PD-L1 is expressed in the context of $\mathrm{T}$ cell exhaustion during chronic viral infection (e.g. HPV infection) and by tumor cells (TCs) [10-12]. The presence of PD-L1 on TCs contributes to the process of immune evasion [13], hence PD-L1 expression is confirmed to be a marker of poor prognosis in the majority of solid tumors [14]. In the context of SCCHN (including OSCC) there is no consensus yet on the role of PD-L1 expression as a prognostic biomarker [15-18]. Multiple antibody (Ab) clones are currently analyzed for PD-L1 expression on cancer cells and in the cancer microenvironment using different immunohistochemical staining platforms or in-house staining procedures, often yielding different staining patterns. Moreover, read-out of PD-L1 positivity can be done on TCs as well as on ICs in the tumor microenvironment. This methodological complexity only contributes to the contradictorily results on the value of PD-L1 as biomarker. Therefore, the aim of this study was to perform additional research on the role of PD-L1 in SCCHN, focusing only on OSCC, using two clones from FDA approved kits, namely the 22C3 clone (Agilent-DAKO) and the SP142 clone (Roche), and scoring both TCs and ICs. We evaluated the expression of PD-L1 in OSCC and looked for associations with clinicopathological variables and the amount and type of tumor infiltrating lymphocytes (TILs). In addition we assessed the effect of PD-L1 status and the tumor immune cell infiltrate on outcome.

\section{RESULTS}

\section{Patient characteristics}

The 99 patients included in this study were predominantly male $(83 \%)$, and represented primarily stage III/IV tumors $(83 \%)$. Most of the tumors originated from the tonsil $(43 \%)$ and were moderately $(62 \%)$ differentiated. The overall HPV prevalence rate was $19 \%$ (19/99) with no difference in distribution along all topographic sites $(P=0.5673)$. More $\mathrm{HPV}^{+}$specimens were detected among poorly differentiated and basaloid tumors $(11 / 32)$ compared to well/moderately differentiated tumors $(8 / 67 ; P=0.0265)$. in Table 1.

\section{The pattern of PD-L1 expression}

\section{Tumor cells (TCs)}

Using the SP142 clone for evaluation of PD-L1 expression, PD-L1 status of TCs was categorized as follows: IHC 0 (58\%), IHC 1 (15\%), IHC 2 (12\%) and IHC $3(10 \%)$. Five samples (5\%) could not be evaluated. Using the $22 \mathrm{C} 3$ clone, distribution of tumoral IHC scores was as follows: IHC 0 (45\%), IHC 1 (20\%), IHC $2(13 \%)$ and IHC $3(20 \%)$. Two samples (2\%) could not be evaluated. PD-L1 positivity defined as $\geq 5 \%$ PD-L1 expression on TCs resulted in 23\% (22/94) and 34\% (33/97) PD-L1 ${ }^{+}$tumor specimens for the SP142 and 22C3 clone, respectively (Table 1).

\section{Immune cells (ICs)}

Only little tumor infiltrating ICs expressed PD-L1 (SP142 clone) with IHC 0 in 76 cases (77\%), IHC 1 in 9 cases $(9 \%)$, IHC 2 in one case $(1 \%)$ and IHC 3 in one case (1\%). Twelve samples (12\%) were not evaluable. Similar to the SP142 clone, low expression was observed on ICs for the $22 \mathrm{C} 3$ clone: IHC 0 in $66 \%$ of cases, IHC 1 in $16 \%$ of cases, IHC 2 in $3 \%$ of cases and no IHC 3 . Thirteen samples could not be evaluated.

\section{Relation of PD-L1 expression on TCs with different clinicopathological variables}

A positive link was found between HPV status and PD-L1 positivity on TCs for the SP142 clone $(P<0.0001)$ and 22C3 clone $(P=0.0649)$. Next, positive SP142 PDL1 expression was associated with poorly differentiated/ basaloid tumors $(15 / 29$ versus $7 / 65 ; P=0.0001)$ whereas positive 22C3 PD-L1 expression on TCs was most common in elder patients $(8 / 12$ versus $25 / 85 ; P=0.0234)$ and in poorly differentiated/basaloid tumors (17/31 versus 16/66; $P=0.0111)$.

All associations between PD-L1 on TCs and clinicopathological variables are presented in Table 1.

\section{Relation of PD-L1 expression on TCs with TILs}

Notably, PD-L1 positivity on TCs was linked with the immune environment, as this parameter was associated with increased TIL count $(P<0.0001$ and $P=0.0009)$, $\mathrm{CD}^{+} \mathrm{T}$ cell count $(P=0.0009$ and $P=0.0044), \mathrm{CD}^{+}$ T cell count $(P<0.0001$ and $P=0.0001)$ and FoxP3 ${ }^{+} \mathrm{T}$ cell count $(P=0.0004$ and $P=0.0094)$ for the SP142 and 22C3 clone, respectively.

All associations with TILs are given in Table 2.

\section{Relation of PD-L1 expression on TCs with clinical outcome}

Positive PD-L1 expression using the SP142 clone resulted in a more favorable outcome with median overall 
Table 1: Association between PD-L1 on tumor cells, $\mathrm{CD8}^{+} \mathrm{T}$ cells and clinicopathological variables

\begin{tabular}{|c|c|c|c|c|c|c|c|c|c|c|}
\hline \multirow{2}{*}{ Parameter } & \multirow[t]{2}{*}{ Overall } & \multicolumn{3}{|c|}{ SP142 PD-L1 } & \multicolumn{3}{|c|}{ 22C3 PD-L1 } & \multicolumn{3}{|c|}{$\mathrm{CD8}^{+} \mathrm{T}$ cell count } \\
\hline & & Negative & Positive & $P$-value & Negative & Positive & $P$-value & Low & High & $P$-value \\
\hline Patient number & $99(100)$ & $72(77)$ & $22(23)$ & & $64(66)$ & $33(34)$ & & $67(77)$ & $20(23)$ & \\
\hline \multicolumn{11}{|l|}{ Age } \\
\hline$<50$ years & $13(13)$ & $11(11)$ & $1(1)$ & \multirow{3}{*}{$0.1522 *$} & $10(10)$ & $2(2)$ & \multirow{3}{*}{$0.0234 \%$} & $8(9)$ & $1(1)$ & \multirow{3}{*}{0.0248} \\
\hline $50-69$ years & $74(75)$ & $54(57)$ & $16(17)$ & & $50(52)$ & $23(24)$ & & $54(62)$ & $13(15)$ & \\
\hline$\geq 70$ years & $12(12)$ & 7 (7) & $5(5)$ & & $4(4)$ & $8(9)$ & & $5(6)$ & $6(7)$ & \\
\hline \multicolumn{11}{|l|}{ Gender } \\
\hline Female & $17(17)$ & $12(13)$ & $5(5)$ & \multirow{2}{*}{0.5351} & $12(13)$ & $5(5)$ & \multirow{2}{*}{0.7820} & $14(16)$ & $3(3)$ & \multirow{2}{*}{0.7515} \\
\hline Male & $82(83)$ & $60(64)$ & $17(18)$ & & $52(54)$ & $28(29)$ & & $53(61)$ & $17(20)$ & \\
\hline \multicolumn{11}{|l|}{ Tumor site } \\
\hline Tonsil & $43(43)$ & $29(31)$ & $13(14)$ & \multirow{4}{*}{$0.2108^{*}$} & $23(24)$ & $20(21)$ & \multirow{3}{*}{$0.1621^{*}$} & $28(32)$ & $10(12)$ & \multirow{3}{*}{$0.1330^{*}$} \\
\hline Tongue base & $12(12)$ & $5(5)$ & $5(5)$ & & $6(6)$ & $5(5)$ & & $5(6)$ & $4(5)$ & \\
\hline Other sites & $23(23)$ & $17(18)$ & $4(4)$ & & $17(18)$ & $5(5)$ & & $17(20)$ & $2(2)$ & \\
\hline Multiple subsites & $21(21)$ & $21(22)$ & $0(0)$ & & $18(19)$ & $3(5)$ & - & $17(20)$ & $4(5)$ & - \\
\hline \multicolumn{11}{|l|}{ T stage } \\
\hline $\mathrm{T}_{1-2}$ & $56(57)$ & $39(42)$ & $16(17)$ & \multirow{2}{*}{0.1441} & $32(33)$ & $23(24)$ & \multirow{2}{*}{$0.0650 *$} & $32(37)$ & $17(20)$ & \multirow{2}{*}{0.0041} \\
\hline $\mathrm{T}_{3-4}$ & $43(43)$ & $33(35)$ & $6(6)$ & & $32(33)$ & $10(10)$ & & $35(40)$ & $3(3)$ & \\
\hline \multicolumn{11}{|l|}{$\mathrm{N}$ stage } \\
\hline $\mathrm{N}_{0}$ & $30(30)$ & $23(25)$ & $4(4)$ & \multirow{3}{*}{$0.2100^{*}$} & $21(22)$ & $8(8)$ & \multirow{3}{*}{$0.0939 *$} & $19(22)$ & $5(6)$ & \multirow{3}{*}{$0.6038^{*}$} \\
\hline $\mathrm{N}_{1}$ & $14(14)$ & $12(13)$ & $2(2)$ & & $12(12)$ & $2(2)$ & & $12(14)$ & $2(2)$ & \\
\hline $\mathrm{N}_{2-3}$ & $55(56)$ & $37(39)$ & $16(17)$ & & $31(32)$ & $23(24)$ & & $36(41)$ & $13(15)$ & \\
\hline \multicolumn{11}{|l|}{ Prognostic stage } \\
\hline $\mathrm{I} / \mathrm{II}$ & $17(17)$ & $15(16)$ & $2(2)$ & 03430 & $12(13)$ & $5(5)$ & 07820 & $10(12)$ & $4(5)$ & 07201 \\
\hline III/IV & $82(83)$ & $57(61)$ & $20(21)$ & 0.0450 & $52(54)$ & $28(29)$ & 0.1020 & $57(66)$ & $16(18)$ & 0.1291 \\
\hline $\begin{array}{l}\text { Grade of } \\
\text { differentiation }\end{array}$ & & & & & & & & & & \\
\hline Well/moderately & $67(68)$ & $58(62)$ & $7(7)$ & & $50(52)$ & $16(17)$ & & $52(60)$ & $8(9)$ & \\
\hline Poorly & $19(19)$ & $8(8)$ & $10(10)$ & $0.0001 *$ & $8(8)$ & $11(11)$ & 0.0111* & $6(7)$ & $9(10)$ & $0.0006 *$ \\
\hline Basaloid & $13(13)$ & $6(6)$ & $5(5)$ & & $6(6)$ & $6(6)$ & & $9(10)$ & $3(3)$ & \\
\hline HPV status & & & & & & & & & & \\
\hline Negative & $80(81)$ & $66(70)$ & $11(12)$ & $<00001$ & $55(57)$ & $23(24)$ & 00640 & $57(66)$ & $13(15)$ & 00591 \\
\hline Positive & $19(19)$ & $6(6)$ & $11(12)$ & -0.0001 & $9(9)$ & $10(10)$ & 0.0049 & $10(12)$ & $7(8)$ & 0.0591 \\
\hline Primary therapy & & & & & & & & & & \\
\hline Surgery & $51(52)$ & $34(36)$ & $15(16)$ & & $31(31)$ & $19(20)$ & & $32(37)$ & $11(13)$ & \\
\hline Radiotherapy & $25(25)$ & $18(19)$ & $5(5)$ & $0.1374 *$ & $16(17)$ & $9(9)$ & $0.4390 *$ & $15(17)$ & $8(9)$ & $0.0521 *$ \\
\hline Chemoradiotherapy & $23(23)$ & $20(21)$ & $2(2)$ & & $17(18)$ & $5(5)$ & & $20(23)$ & $1(1)$ & \\
\hline
\end{tabular}

Data given are numbers, percentages are given between brackets (\%). Overall column displays total numbers (\%). Cut-off values were taken at median values ( $3+$ : abundant occurrence of $\mathrm{CD} 8^{+} \mathrm{T}$ cells) and at $\geq 5 \%$ for PD-L1 on TCs (SP142 clone and $22 \mathrm{C} 3$ clone). Samples that were classified as 'impossible to evaluate' were not included in the analysis. $P$-value calculated by Fisher exact test unless otherwise indicated ( ${ }^{*} P$-value calculated by Chi-square test). HPV, human papillomavirus.

survival (OS) of 9.8 years versus 4.1 years for SP142 PDL1 negativity (hazard ratio $[\mathrm{HR}]=0.51[0.31-0.99], P=$ 0.0466; Figure 1A) whereas 22C3 PD-L1 expression on TCs showed no significant association with OS (4.0 years versus 4.4 years; $\mathrm{HR}=0.99$ [0.58-1.72], $P=0.9846$; Figure 1B). None of the PD-L1 markers was associated with prolonged disease-free survival (DFS) (HR SP142
$=0.43[0.22-1.16], P=0.1070$ and $\mathrm{HR} 22 \mathrm{C} 3=1.28$ [0.60-2.83], $P=0.5110$; Figure 1C-1D). An overview of the HRs on DFS for all tumor markers, IC markers and associated clinicopathological markers is given in Supplementary Table 1.

The relation between TILs and outcome was evaluated as well. High TIL count, high $\mathrm{CD}^{+} \mathrm{T}$ cell count and high 
Table 2: Association between PD-L1 on tumor cells and stromal immune cell infiltrate

\begin{tabular}{|c|c|c|c|c|c|c|c|}
\hline \multirow{2}{*}{ Parameter } & \multirow[t]{2}{*}{ Overall } & \multicolumn{3}{|c|}{ SP142 PD-L1 } & \multicolumn{3}{|c|}{ 22C3 PD-L1 } \\
\hline & & Negative & Positive & $P$-value & Negative & Positive & $P$-value \\
\hline Patient number & $99(100)$ & $72(77)$ & $22(23)$ & & $64(66)$ & $33(34)$ & \\
\hline \multicolumn{8}{|l|}{ TIL count } \\
\hline $1+$ & $12(12)$ & $12(14)$ & $0(0)$ & \multirow{4}{*}{$<0.0001$} & $11(12)$ & $1(1)$ & \multirow{5}{*}{0.0009} \\
\hline $2+$ & $42(42)$ & $37(42)$ & $3(3)$ & & $32(36)$ & $9(10)$ & \\
\hline$\underline{3+}$ & $26(26)$ & $14(16)$ & $11(13)$ & & $13(14)$ & $13(14)$ & \\
\hline $4+$ & $11(11)$ & $4(5)$ & $7(8)$ & & $3(3)$ & $8(9)$ & \\
\hline ITE & $8(8)$ & & & & & & \\
\hline \multicolumn{8}{|l|}{$\mathrm{CD}^{+} \mathrm{T}$ cell count } \\
\hline $1+$ & $20(20)$ & $18(21)$ & $0(0)$ & \multirow{5}{*}{0.0009} & $15(17)$ & $4(5)$ & \multirow{5}{*}{0.0044} \\
\hline $2+$ & $33(33)$ & $28(32)$ & $5(6)$ & & $26(29)$ & $8(9)$ & \\
\hline$\underline{\mathbf{3}+}$ & $19(19)$ & $12(14)$ & $7(8)$ & & $12(14)$ & $7(8)$ & \\
\hline $4+$ & $17(17)$ & $8(9)$ & $9(10)$ & & $5(6)$ & $12(14)$ & \\
\hline ITE & $10(10)$ & & & & & & \\
\hline \multicolumn{8}{|l|}{$\mathrm{CD}^{+} \mathrm{T}$ cell count } \\
\hline $1+$ & $36(36)$ & $34(40)$ & $2(2)$ & \multirow{4}{*}{$<0.0001$} & $30(35)$ & $7(8)$ & \multirow{4}{*}{0.0001} \\
\hline $2+$ & $31(31)$ & $24(28)$ & $5(6)$ & & $22(25)$ & $8(9)$ & \\
\hline$\underline{3+}$ & $20(20)$ & $8(9)$ & $12(14)$ & & $5(6)$ & $15(17)$ & \\
\hline ITE & $12(12)$ & & & & & & \\
\hline \multicolumn{8}{|l|}{ FoxP $^{+} \mathrm{T}$ cell count } \\
\hline $1+$ & $58(59)$ & $51(59)$ & $7(8)$ & \multirow{3}{*}{$0.0004 *$} & $44(49)$ & $15(17)$ & \multirow{3}{*}{0.0094} \\
\hline$\underline{2+}$ & $31(31)$ & $15(17)$ & $14(16)$ & & $14(16)$ & $16(18)$ & \\
\hline ITE & $10(10)$ & & & & & & \\
\hline
\end{tabular}

Data given are numbers, percentages are given between brackets (\%). Cut-off values were taken at $\geq 5 \%$ for PD-L1 on TCs (SP142 clone and 22C3 clone). Parameters in bold and underlined represent median cut-off values used for survival analysis: $3+$ (TIL count, $\mathrm{CD}^{+} \mathrm{T}$ cell count and $\mathrm{CD} 8^{+} \mathrm{T}$ cell count) and $2+\left(\mathrm{FoxP}^{+} \mathrm{T}\right.$ cell count). Samples that were classified as 'impossible to evaluate' were not included in the analysis. P-value calculated by Chi-square test unless otherwise indicated (* P-value calculated by Fisher exact test). ITE, impossible to evaluate; TIL, tumor-infiltrating lymphocyte.

$\mathrm{CD}^{+} \mathrm{T}$ cell count but not FoxP3 ${ }^{+} \mathrm{T}$ cell count proved to have a favorable influence on OS (Supplementary Figure 1). Particularly, an elevated $\mathrm{CD} 8^{+} \mathrm{T}$ cell count was significantly associated with prolonged OS (9.8 years) versus patients with a low $\mathrm{CD}^{+} \mathrm{T}$ cell count $(3.5$ years; $\mathrm{HR}=0.32$ [0.22-0.71], $P$ $=0.0020$ ). As $\mathrm{CD}^{+} \mathrm{T}$ cell count proved the strongest marker of the immune cell infiltrate, an analysis was performed combining $\mathrm{CD}^{+} \mathrm{T}$ cell count and PD-L1 expression on TCs. The combined analysis of SP142 PD-L1 expression on TCs and $\mathrm{CD}^{+} \mathrm{T}$ cell count showed that this combination was significantly correlated with OS: median OS of 9.8 years, not reached, 2.4 years and 4.0 years for the $\mathrm{PD}-\mathrm{L1}^{+} /$high $\mathrm{CD}^{+}$, $\mathrm{PD}-\mathrm{L1}^{-} /$high $_{\mathrm{CD}}{ }^{+}, \mathrm{PD}-\mathrm{L1}^{+} /$low $\mathrm{CD}^{+}$, and $\mathrm{PD}-\mathrm{L1}^{-} /$ low $\mathrm{CD}^{+}$cohorts, respectively $(P=0.0321$; Figure $2 \mathrm{~A})$. Similar, a significance was found for combining 22C3 PDL1 expression on TCs and CD8 ${ }^{+} \mathrm{T}$ cell count with median OS of 9.8 years, not reached, 2.1 years and 4.1 years for the respective cohorts $(P=0.0118$; Figure $2 \mathrm{~B})$. As the majority of patients were stratified as $\mathrm{PD}-\mathrm{L1}^{-} /$low $\mathrm{CD}^{+}$, patients were bicategorically categorized as 'at least one variable positive' versus $\mathrm{PD}-\mathrm{L} 1^{-} /$low $\mathrm{CD}^{+}$. Patients with 'at least one variable positive' had a more favorable outcome for the SP142 PD-L1 expression (median OS 9.8 years versus 4.0 years; $\mathrm{HR}=0.40$ [0.24-0.78], $P=0.0048$; Figure 2C) but not for the $22 \mathrm{C} 3$ PD-L1 expression (median OS 5.5 years versus 4.1 years; $\mathrm{HR}=0.66$ [0.38-1.15], $P=0.1415$; Figure 2D).

In the multivariate model, which adjusted for HPV status, $\mathrm{CD}^{+} \mathrm{T}$ cell count proved to be the independent prognosticator for $\mathrm{OS}(\mathrm{HR}=0.31 \quad[0.14-0.70]$; $P=0.0050)$ whereas SP142 PD-L1 positivity and other immune cell counts did not contribute to the model. When assessing the combination of SP142 PD-L1 expression and $\mathrm{CD}^{+} \mathrm{T}$ cell count in the multivariate model, patients with 'at least one variable positive' had an OS benefit compared with $\mathrm{PD}-\mathrm{L} 1$ - /low $\mathrm{CD}^{+}$patients $(\mathrm{HR}=0.39$ [0.20-0.78]; $P=0.0070$ ). 
An overview of all multivariate $\mathrm{HR}$ is given in Table 3.

\section{Relation of PD-L1 expression on ICs with clinicopathological variables, TILs and clinical outcome}

No relation was demonstrated between PDL1 expression (SP142 or 22C3 clone) on ICs and clinicopathological variables, including TILs, overall and disease-free survival.

\section{DISCUSSION}

In our study, positive PD-L1 expression on TCs using the SP142 clone was noticed in $23 \%$ of specimens whereas $34 \%$ of specimens were PD-L1 ${ }^{+}$according to the $22 \mathrm{C} 3$ clone ( $\geq 5 \%$ cut-off). The number of $\mathrm{PD}-\mathrm{L}^{+}$samples is considerably lower in comparison to other previously reported data on the expression of PD-L1 in OSCC $[19,20]$. These differences might be partially explained by the difference in sample size. However, the main
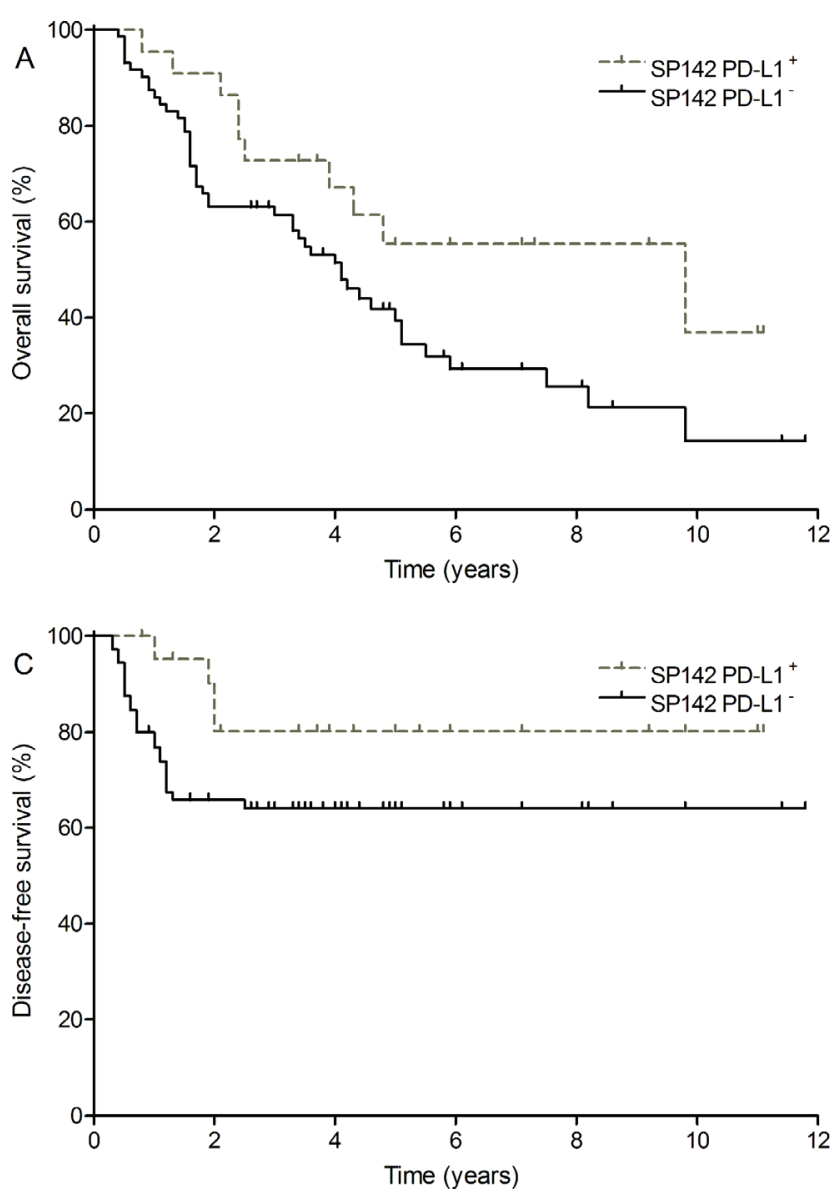

confounder for the lower PD-L1 expression is probably the use of different $\mathrm{Ab}$ clones. Each $\mathrm{Ab}$ targets different epitopes of PD-L1 with different affinity, resulting in different staining patterns [21]. When considering PD-L1 as a biomarker in daily clinical practice, one should be aware of these methodological concerns and validation and quality assessment of this immunohistochemical marker will prove to be of the utmost importance.

The study of PD-L1 expression on ICs did not add useful data to our study, probably because of the very low expression levels (98\% of the samples using the SP142 clone and $97 \%$ of the samples using the $22 \mathrm{C} 3$ clone $\left[\geq 5 \%\right.$ cut-off] were $\mathrm{PD}-\mathrm{L1}^{-}$). The expression of PD-L1 on tumor infiltrating ICs is well known but further research is warranted in order to evaluate its contribution to the (anti-) tumor immune response and its link with PD-L1 expression on TCs.

We found PD-L1 expression on TCs determined by SP142 and 22C3 staining to be positively associated with high number of TILs, high $\mathrm{CD}^{+} \mathrm{T}$ cell count, high $\mathrm{CD}^{+}$ $\mathrm{T}$ cell count and high FoxP3 ${ }^{+} \mathrm{T}$ cell count. These findings reflect the hypothesis that a PD-L1 mediated adaptive
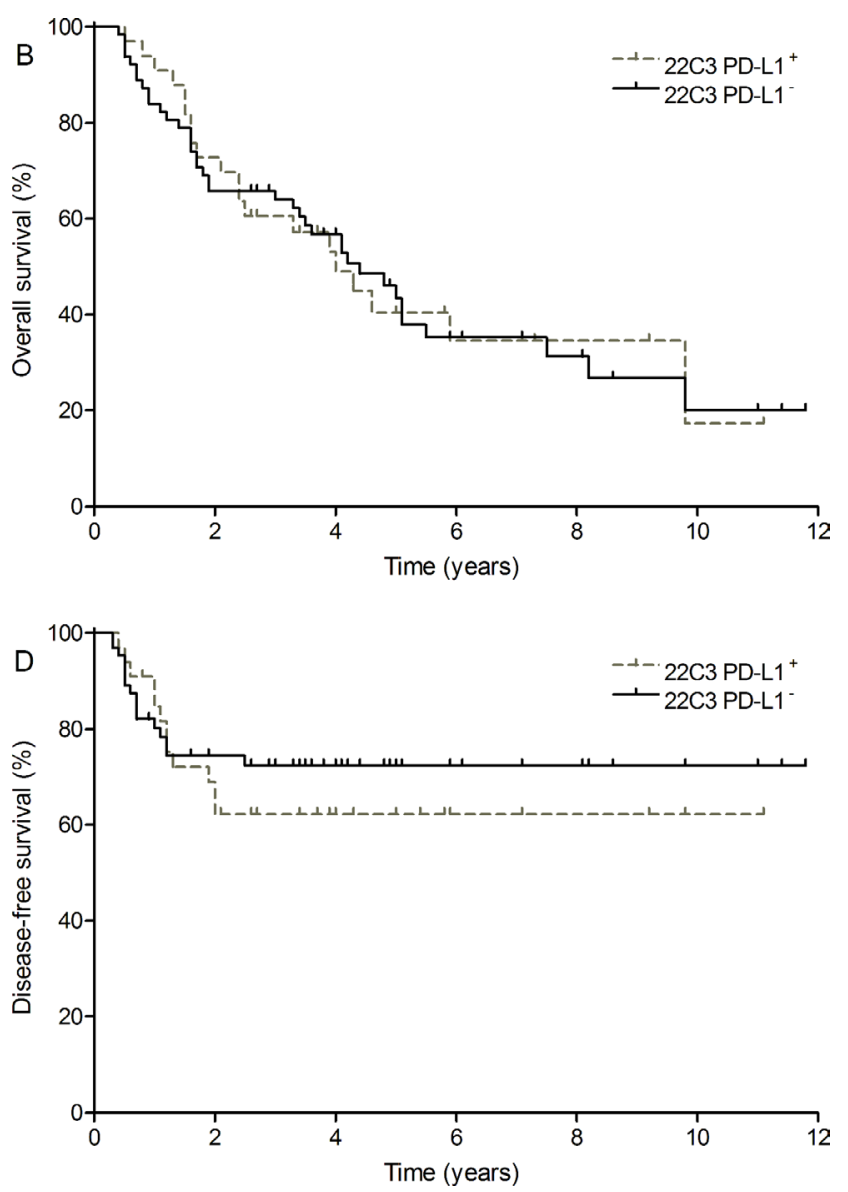

Figure 1: Survival outcome of PD-L1 expression. (A) OS of SP142 PD-L1 (0.51 [0.31-0.99], $P=0.0466)$; (B) OS of 22C3 PD-L1 (0.99 [0.58-1.72], $P=0.9846)$; (C) DFS of SP142 PD-L1 (0.43 [0.22- 1.16], $P=0.1070)$ and (D) DFS of 22C3 PD-L1 (1.28 [0.60-2.83], $P=0.5110)$. Cut-off values were taken at $\geq 5 \%$ for PD-L1 on TCs (SP142 and 22C3 clone). 
Table 3: Multivariate Cox regression model for overall survival outcome

\begin{tabular}{|c|c|c|c|c|}
\hline \multirow{2}{*}{ Parameter } & \multicolumn{2}{|c|}{ Separate immune markers } & \multicolumn{2}{|c|}{ Combination of immune markers } \\
\hline & Multivariate HR (95\% CI) & $P$-value & Multivariate HR (95\% CI) & $P$-value \\
\hline \multicolumn{5}{|l|}{ HPV status } \\
\hline Negative & 1 & & 1 & \\
\hline Positive & $0.55(0.21-1.43)$ & 0.2213 & $0.61(0.25-1.49)$ & 0.2786 \\
\hline \multicolumn{5}{|l|}{ TIL count } \\
\hline Low & 1 & & 1 & \\
\hline High & $1.06(0.48-2.35)$ & 0.8828 & $1.11(0.49-2.52)$ & 0.7976 \\
\hline \multicolumn{5}{|l|}{$\mathrm{CD}^{+} \mathrm{T}$ cell count } \\
\hline Low & 1 & & 1 & \\
\hline High & $0.94(0.45-1.97)$ & 0.8660 & $0.77(0.37-1.61)$ & 0.4859 \\
\hline \multicolumn{5}{|l|}{$\mathrm{CD}^{+} \mathrm{T}$ cell count } \\
\hline Low & 1 & & & \\
\hline High & $0.31(0.14-0.70)$ & 0.0050 & & \\
\hline \multicolumn{5}{|l|}{ SP142 PD-L1 } \\
\hline Negative & 1 & & & \\
\hline Positive & $0.98(0.35-2.74)$ & 0.9689 & & \\
\hline \multicolumn{5}{|c|}{ Combination SP142 PD-L1/CD8 ${ }^{+} \mathrm{T}$ cell count } \\
\hline PD-L1-/low CD $^{+}$ & & & 1 & \\
\hline At least 1 positive/high & & & $0.39(0.20-0.78)$ & 0.0070 \\
\hline
\end{tabular}

Multivariate HRs were calculated through a Cox proportional-hazards regression model. Multivariate analysis was performed for $\mathrm{CD}^{+} \mathrm{T}$ cell count and SP142 PD-L1 as separate immune markers or as combined immune markers. Cut-off values were taken at median values (3+: abundant occurrence of TILs, CD3 ${ }^{+} \mathrm{T}$ cells and $\mathrm{CD} 8^{+} \mathrm{T}$ cells) and at $\geq 5 \%$ for PD-L1 on tumor cells (SP142 clone). HPV, human papillomavirus; HR, hazard ratio; TIL, tumor-infiltrating lymphocyte.

immune resistance is induced following interferongamma secretion by TILs [22]. It is reported that PD-L1 expression is visually higher in areas with high $\mathrm{T}$ cell infiltrate and this finding is confirmed in our study [23]. PD-L1 was also associated with positive HPV status which in turn was nearly significantly associated with $\mathrm{CD}^{+} \mathrm{T}$ cells. As PD-L1 expression is observed in the deep invaginations of tonsillar crypts in non-cancerous tonsils as well, this observation might suggest that virus induced malignant transformation could be enhanced in the reticulated epithelium of tonsillar crypts in the presence of PD-L1.

Survival analysis revealed that PD-L1 positivity of TCs, using the SP142 clone, was related to better OS but not with DFS in univariate analysis. Also high $\mathrm{CD}^{+}$ $\mathrm{T}$ cell count showed prognostic OS benefit in OSCC, irrespective of the HPV status. As both $\mathrm{CD}^{+} \mathrm{T}$ cell count and PD-L1 status were related to a better OS, their effect was even more pronounced when using a combined prognostic biomarker based on PD-L1 status plus $\mathrm{CD}^{+} \mathrm{T}$ cell count. Having 'at least one variable positive' resulted in an increased survival outcome compared to patients who were stratified as PD-L1-/low $\mathrm{CD}^{+}$. The link of PDL1 with T-cell infiltrate and HPV status as demonstrated by our own study should at least partially be accounted for this observation. The fact that $\mathrm{PD}-\mathrm{L}^{+}$tumors and high infiltration of $\mathrm{CD}^{+} \mathrm{T}$ lymphocytes showed better survival outcome might come across as a paradox since high $\mathrm{CD}^{+}$lymphocyte count indicates an active immune response with anti-tumor effect whereas PD-L1 positivity is assumed to dampen this response. This observation demonstrates that PD-L1 expression cannot be interpreted simply as a marker of immune suppression but rather reflects a response to (over-) activation of an endogenous inflammatory immune response at the tumor site [23, 24].

To our knowledge, this is the first study to evaluate the expression of PD-L1 in OSCC using two monoclonal Abs (SP142 clone and 22C3 clone) from FDA approved kits that are currently used in various clinical trials. Pharmacodiagnostic testing for anti-PD-(L)1 therapy is nowadays mainly performed with two clones from Agilent-DAKO and two clones from Roche. Recently, it was reported that staining results for the $22 \mathrm{C} 3$ clone are in concordance with those obtained from the 28-8 and SP263 clone, but not with those of the SP142 clone $[25,26]$ and this incited us to focus on the 22C3 and SP142 clone for this study. Besides, we chose to include tumors arising from one primary tumor site. Although SCCHN is often considered one entity, recent publications report a heterogeneous molecular and immunological tumor 
profile of these malignancies on different anatomical localizations $[27,28]$. Therefore it is desirable to focus on one tumor site rather than on SCCHN in general and thus we restricted the assessment of PD-L1 expression to a well-defined population of patients with tumors arising from the oropharynx.

Also, we deliberately chose to work with formalinfixed, paraffin-embedded (FFPE) samples from biopsies or resections as this is the material that will be available for prognostic biomarker testing in the future. Although biopsy samples might harbor sampling errors and suffer from spatial heterogeneity in PD-L1 expression, it is important to include these samples in the trials to avoid selection bias. It remains however important to evaluate the concordance of PD-L1 expression between different available clones, between different cut-off values and between samples from different origins (e.g. biopsy versus resection specimens).

In conclusion our results demonstrate that $\mathrm{CD}^{+}$ TILs constitute a strong positive prognostic marker in
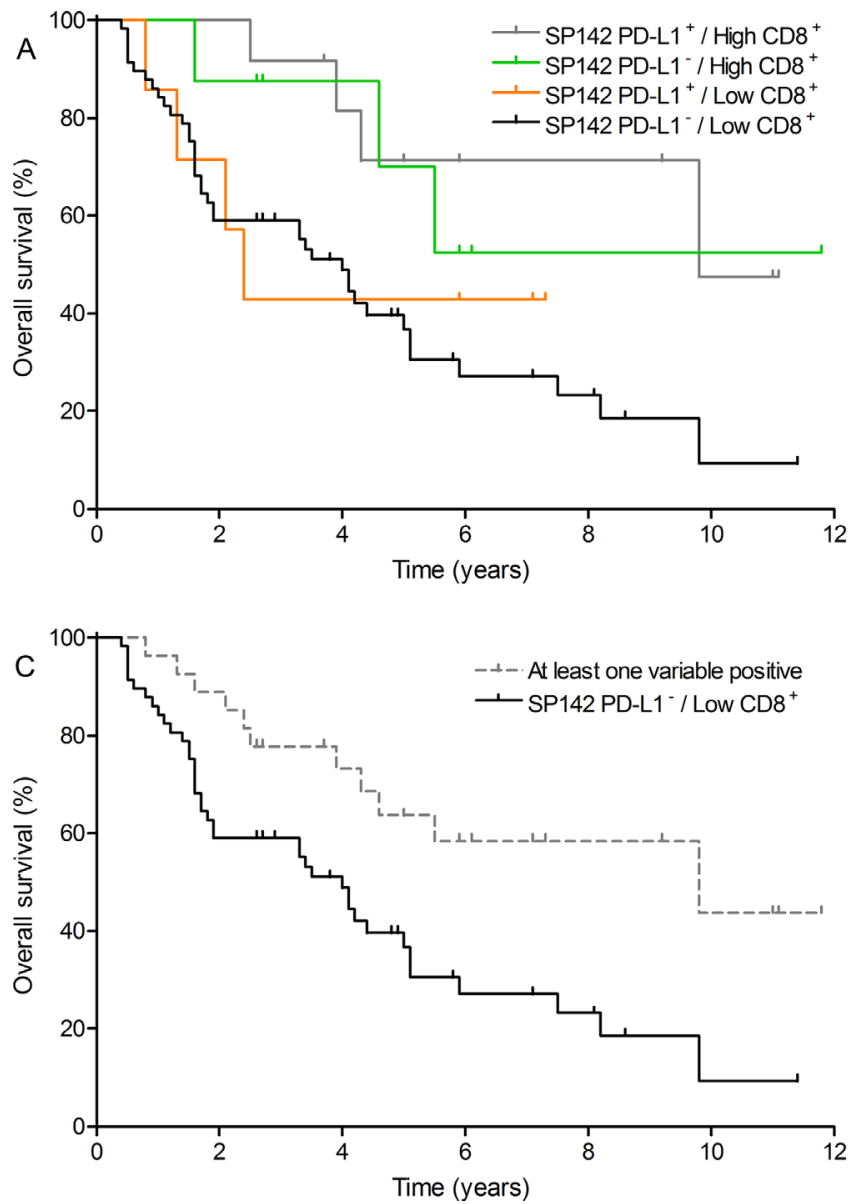

patients diagnosed with OSCC. Furthermore, PD-L1 expression on TCs, assessed by the SP142 clone, also tends to have a positive effect on patient outcome in OSCC. The results of this retrospective study should be confirmed in prospective trials to assess the clinical impact of the biomarkers on routine daily practice. Herein, special attention should be given to methodological issues on PDL1 testing that were also of concern in this study, such as choice of $\mathrm{Ab}$ clone, interpretation criteria and sample type.

\section{MATERIALS AND METHODS}

\section{Study population}

Ninety-nine patients with histologically proven OSCC (anno 2004-2013) were selected from the archival database of the Department of Pathology, Ghent University Hospital. Patients were excluded from the study in case of recurrent or distant metastatic disease. When available, samples from resection specimens were
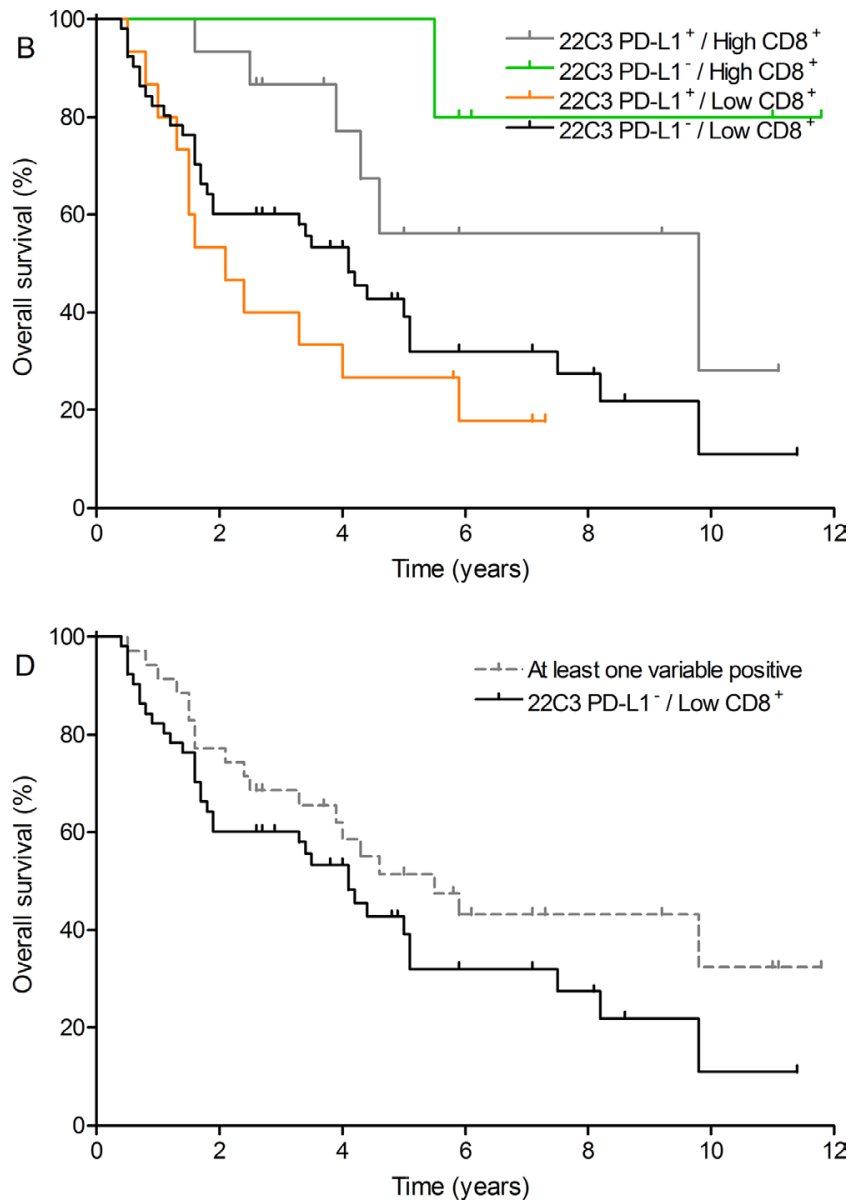

Figure 2: Overall survival outcome combining PD-L1 expression on tumor cells with CD8 ${ }^{+}$T cell count. (A) SP142 PDL1/CD8 ${ }^{+} \mathrm{T}$ cell count: all groups $(P=0.0321)$; (B) $22 \mathrm{C} 3 \mathrm{PD}-\mathrm{L} 1 / \mathrm{CD} 8^{+} \mathrm{T}$ cell count: all groups $(P=0.0118) ;(\mathrm{C}) \mathrm{SP} 142 \mathrm{PD}-\mathrm{L} 1 / \mathrm{CD} 8^{+} \mathrm{T}$ cell count: $\mathrm{PD}-\mathrm{L} 1-/$ low $\mathrm{CD}^{+}$versus at least one variable positive $(0.40[0.24-0.78], P=0.0048)$ and $(\mathrm{D}) 22 \mathrm{C} 3 \mathrm{PD}-\mathrm{L} 1 / \mathrm{CD} 8^{+} \mathrm{T}$ cell count: $\mathrm{PD}-$ $\mathrm{L1}^{-} /$low $\mathrm{CD}^{+}$versus at least one variable positive (0.66 [0.38-1.15], $\left.P=0.1415\right)$. Cut-off values were taken at median values (3: abundant occurrence of CD8+ T cells) and at $\geq 5 \%$ for PD-L1 on tumor cells (SP142 and 22C3 clone). 
preferred for further analysis $(n=27)$, if not, endoscopic biopsy material was used $(n=72)$.

The study was approved by the ethics committee of the Ghent University Hospital.

Clinical, treatment and follow-up data were retrieved from the electronic patient data file. Tumor sites consisted of tonsil, tongue base, other (e.g. tonsillar pillars, posterior wall, vallecula) or multiple subsites involved. The majority of the patients was treated surgically $(n=$ $51)$ by either tumor resection with or without lymph node dissection ( $n=19$ and $n=8$, respectively) or lymph node dissection alone $(n=24)$. Forty-six out of 51 surgically patients received adjuvant treatment, that is, concurrent chemoradiotherapy $(n=30)$ or radiotherapy alone $(n=16)$. Clinical data and treatment details are presented in Table 1. For all patients, treatment decisions were discussed in a multidisciplinary meeting consisting of dedicated head and neck surgeons, medical and radiation oncologists, radiologists and pathologists.

\section{HPV status}

HPV status was determined on FFPE material by high-risk HPV in situ hybridization (ISH) using the Inform HPV III Family B probe (Ventana Medical Systems) on a BenchMark XT automated stainer (Ventana Medical Systems) under ISO15189:2012 accreditation. The probe cocktail detects HPV types 16, 18, 31, 33, 35, 39, 45, 51, 52, 56, 58 and 66. The high-risk HPV ISH test was considered positive if a discrete, blue colored, precipitated reaction product within the TCs was observed.

\section{Immunohistochemistry}

Immunohistochemistry for PD-L1 and TILs subtyping was performed using the BenchMark XT instrument (Ventana Medical Systems inc., Arizona, USA). Staining of CD3, CD8 and FoxP3 (DAKO, Glostrup, Denmark) was performed on FFPE tissue slides of $2 \mu \mathrm{m}$ as previously described [29]. For staining of PD-L1, similar antigen retrieval and blocking steps were followed by incubation with the anti-PD-L1 primary Ab (clone 22C3 diluted 1:100 [Agilent-DAKO, United States] and clone SP142 ready-to-use [Roche, Basel, Switzerland]) and DAB detection using the Ultraview kit (Ventana) and the optiview kit (Ventana), respectively, according to the instructions of the manufacturer. Slides were counterstained with hematoxylin.

\section{Scoring of the tumor samples}

First, a hematoxylin-eosin slide was evaluated to confirm the presence of invasive squamous cell carcinoma, to determine the grade of tumor differentiation and/or define basaloid subtype. The infiltration of TILs in tumor stroma was scored semi-quantitatively with a 4-tiered scale $(1+$ to $4+$ ) as previously described $[29,30]$. Representative scoring for stromal TILs is given in Supplementary Figure 2.

Elaborate evaluation of the immune infiltrate in the stromal compartment (i.e. lymphocytes within the intertumoral stroma), was done semi-quantitatively by scoring for $\mathrm{CD}^{+}, \mathrm{CD}^{+}$and $\mathrm{FoxP}^{+} \mathrm{T}$ cell count. For the subtyping of the immune infiltrate, three representative fields were selected and scored using a similar 4-tiered semi-quantitative method as for TIL scoring (1+ to $4+$ ) $[29,30]$ (Supplementary Figure 2). The mean of the separate scores from each of the 3 fields was calculated as final score, ranging from $1+$ to $4+$. Necrotic or ulcerated areas were excluded from evaluation. Criteria to classify samples as 'impossible to evaluate (ITE)' were the following: 1) (virtually) no tumor stroma present, 2) presence of only a
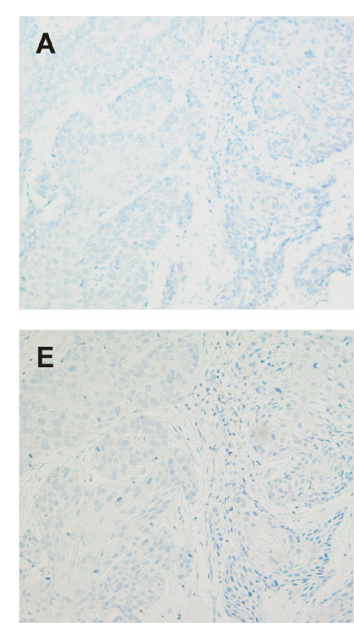
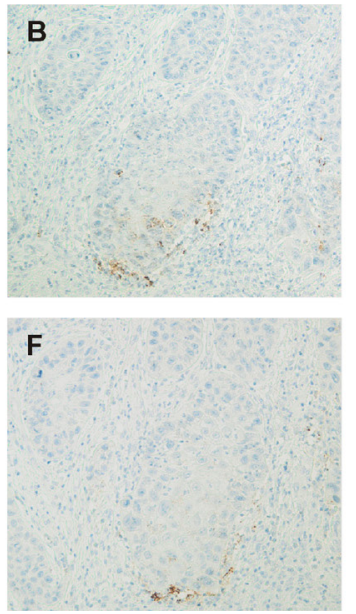
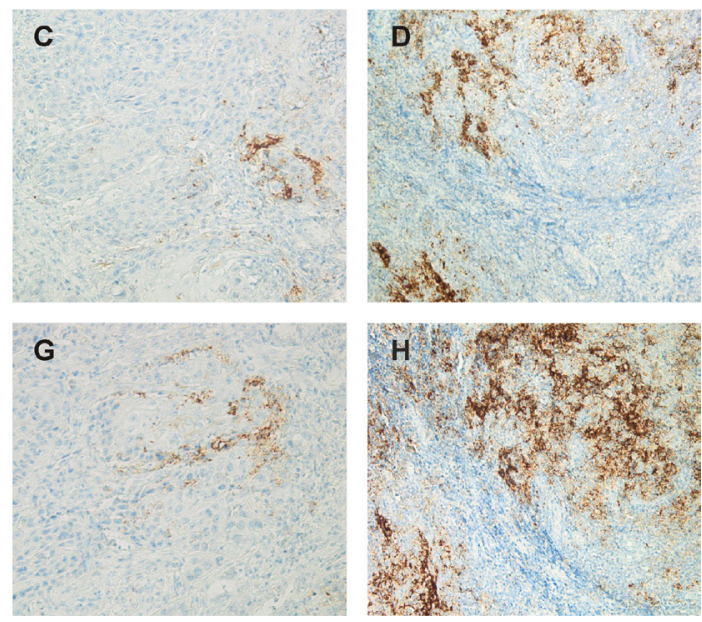

Figure 3: Representative immunohistochemical staining for PD-L1 (x200). PD-L1 expression was determined on TCs. Staining patterns for SP142 PD-L1 were: IHC 0 (A), IHC 1 (B), IHC 2 (C) and IHC 3 (D). Staining patterns for 22C3 PD-L1 were: IHC 0 (E), IHC 1 (F), IHC 2 (G) and IHC 3 (H). Staining with SP142 and 22C3 clone was performed on serial sections $(2 \mu \mathrm{m})$ of the same tumor sample for each IHC score respectively. 
minimal invasive carcinoma component and 3) the inability to differentiate between the ICs of the pre-existing lymphoid tissue of the tonsil and the tumor-associated IC infiltrate.

Subsequently, samples were scored for PD-L1 expression with both the SP142 clone and the 22C3 clone by two independent observers. IHC was scored 0 if $<1 \%$ of TCs were positive, IHC 1 if $\geq 1 \%$ but $<5 \%$ of TCs were positive, IHC 2 if $\geq 5 \%$ but $<10 \%$ of TCs were positive or IHC 3 if $\geq 10 \%$ of TCs were positive (Figure 3) [31]. Mean scores between both observers were used in the analyses. Cut-off values for PD-L1 positivity on TCs were taken at $\geq 5 \%$ (membranous and/or cytoplasmic) for the SP142 and 22C3 clone. PD-L1 expression on ICs was evaluated using Cell`D imaging software (Olympus Corporation, Tokyo, Japan) to ensure objective scoring as the expression of PD-L1 on ICs was low. PD-L1 staining was quantified in the three same representative fields of intertumoral stroma used for scoring of the T cell infiltrate. Scores were given as percentages reflecting the ratio of PD-L1 staining surface area to the whole surface area of the representative field. The final score was determined as the mean of the separate scores from the chosen fields. Again, cut-off values for PD-L1 positivity on ICs were taken at $\geq 5 \%$.

\section{Statistical analysis}

Sample size calculation for a proportional $z$ test of the most fitting immune cell marker $\left(\mathrm{CD}^{+} \mathrm{T}\right.$ cells $)$ has shown that 106 patients are needed to achieve a power of $90 \%\left(\alpha=5 \%\right.$; proportion event group high $\mathrm{CD}^{+}=0.35$; proportion event low $\mathrm{CD}^{+}=0.68$; sample ratio high $\mathrm{CD}^{+} /$low $\mathrm{CD}^{+}=0.29$ ). Associations between categorical variables were determined via Chi-square test. In case of $2 \times 2$ contingency tables with 1 or more observed values lower than 10, a Fisher's Exact test was applied. Secondly, the HR of immunohistochemical parameters on OS and DFS was determined by a log-rank (Mantel-Cox) test. OS was calculated from time from diagnosis on biopsy until day of death or final follow-up whereas DFS was calculated from time of therapy until time of recurrence. For every patient who was not seen in clinic for the preceding 12 months at the point of the survival analysis, the general practitioner was contacted to confirm whether the patient was still alive. Patients that were lost to follow up at either the Ghent University Hospital or the general practitioner were censored in the survival analysis $(n=8)$. Finally, the covariate effect of the risk factors on survival analysis, that reached a $P$ value lower than 0.1 on univariate log-rank test, was determined by means of the Cox proportional hazard model (backward method). Samples that were classified as 'ITE' were not included in the analysis.

\section{ACKNOWLEDGMENTS}

This research was supported by the agency for Innovation by Science and Technology (IWT).

\section{CONFLICTS OF INTEREST}

None.

\section{REFERENCES}

1. Nasman A, Attner P, Hammarstedt L, Du J, Eriksson M, Giraud G, Ahrlund-Richter S, Marklund L, Romanitan M, Lindquist D, Ramqvist T, Lindholm J, Sparen P, et al. Incidence of human papillomavirus (HPV) positive tonsillar carcinoma in Stockholm, Sweden: an epidemic of viralinduced carcinoma? Int J Cancer. 2009; 125:362-366.

2. Chaturvedi AK, Engels EA, Anderson WF, Gillison ML. Incidence trends for human papillomavirus-related and -unrelated oral squamous cell carcinomas in the United States. J Clin Oncol. 2008; 26:612-619.

3. Gillison ML, Koch WM, Capone RB, Spafford M, Westra WH, Wu L, Zahurak ML, Daniel RW, Viglione M, Symer DE, Shah KV, Sidransky D. Evidence for a causal association between human papillomavirus and a subset of head and neck cancers. J Natl Cancer Inst. 2000; 92:709-720.

4. Mellin H, Friesland S, Lewensohn R, Dalianis T, MunckWikland E. Human papillomavirus (HPV) DNA in tonsillar cancer: clinical correlates, risk of relapse, and survival. Int J Cancer. 2000; 89:300-304.

5. Dahlstrand HM, Dalianis T. Presence and influence of human papillomaviruses (HPV) in Tonsillar cancer. Adv Cancer Res. 2005; 93:59-89.

6. Lindquist D, Romanitan M, Hammarstedt L, Nasman A, Dahlstrand H, Lindholm J, Onelov L, Ramqvist T, Ye W, Munck-Wikland E, Dalianis T. Human papillomavirus is a favourable prognostic factor in tonsillar cancer and its oncogenic role is supported by the expression of E6 and E7. Mol Oncol. 2007; 1:350-355.

7. Marur S, D'Souza G, Westra WH, Forastiere AA. HPVassociated head and neck cancer: a virus-related cancer epidemic. Lancet Oncol. 2010; 11:781-789.

8. Ang KK, Harris J, Wheeler R, Weber R, Rosenthal DI, Nguyen-Tan PF, Westra WH, Chung CH, Jordan RC, Lu C, Kim H, Axelrod R, Silverman CC, et al. Human papillomavirus and survival of patients with oropharyngeal cancer. N Engl J Med. 2010; 363:24-35.

9. Attner P, Du J, Nasman A, Hammarstedt L, Ramqvist T, Lindholm J, Marklund L, Dalianis T, Munck-Wikland E. The role of human papillomavirus in the increased incidence of base of tongue cancer. Int J Cancer. 2010; 126:2879-2884.

10. Keir ME, Butte MJ, Freeman GJ, Sharpe AH. PD-1 and its ligands in tolerance and immunity. Annu Rev Immunol. 2008; 26:677-704.

11. Freeman GJ, Long AJ, Iwai Y, Bourque K, Chernova T, Nishimura H, Fitz LJ, Malenkovich $\mathrm{N}$, Okazaki $\mathrm{T}$, Byrne MC, Horton HF, Fouser L, Carter L, et al. Engagement of the PD-1 immunoinhibitory receptor by a 
novel B7 family member leads to negative regulation of lymphocyte activation. J Exp Med. 2000; 192:1027-1034.

12. Latchman $\mathrm{Y}$, Wood CR, Chernova T, Chaudhary D, Borde M, Chernova I, Iwai Y, Long AJ, Brown JA, Nunes R, Greenfield EA, Bourque K, Boussiotis VA, et al. PD-L2 is a second ligand for PD-1 and inhibits T cell activation. Nat Immunol. 2001; 2:261-268.

13. Dong H, Strome SE, Salomao DR, Tamura H, Hirano F, Flies DB, Roche PC, Lu J, Zhu G, Tamada K, Lennon VA, Celis E, Chen L. Tumor-associated B7-H1 promotes T-cell apoptosis: a potential mechanism of immune evasion. Nat Med. 2002; 8:793-800.

14. Wu P, Wu D, Li L, Chai Y, Huang J. PD-L1 and Survival in Solid Tumors: A Meta-Analysis. PLoS One. 2015; 10:e0131403.

15. Kim HS, Lee JY, Lim SH, Park K, Sun JM, Ko YH, Baek CH, Son YI, Jeong HS, Ahn YC, Lee MY, Hong M, Ahn MJ. Association Between PD-L1 and HPV Status and the Prognostic Value of PD-L1 in Oropharyngeal Squamous Cell Carcinoma. Cancer Res Treat. 2016; 48:527-536.

16. Satgunaseelan L, Gupta R, Madore J, Chia N, Lum T, Palme CE, Boyer M, Scolyer RA, Clark JR. Programmed cell death-ligand 1 expression in oral squamous cell carcinoma is associated with an inflammatory phenotype. Pathology. 2016; 48:574-580.

17. Straub M, Drecoll E, Pfarr N, Weichert W, Langer R, Hapfelmeier A, Gotz C, Wolff KD, Kolk A, Specht K. CD274/PD-L1 gene amplification and PD-L1 protein expression are common events in squamous cell carcinoma of the oral cavity. Oncotarget. 2016; 7:12024-12034. https://doi.org/10.18632/oncotarget.7593.

18. Chureemas $\mathrm{T}$, Larbcharoensub $\mathrm{N}$, Juengsamarn $\mathrm{J}$, Layangkool T, Jiarpinitnun C, Chansriwong P, Trachu N, Pattaranutaporn P, Ngamphaiboon N. Prevalence, pattern, and impact of PD-L1 expression and HPV-status in head and neck squamous cell carcinoma. Ann Oncol. 2016; 27:328-350.

19. Lyford-Pike S, Peng S, Young GD, Taube JM, Westra WH, Akpeng B, Bruno TC, Richmon JD, Wang H, Bishop JA, Chen L, Drake CG, Topalian SL, et al. Evidence for a role of the PD-1:PD-L1 pathway in immune resistance of HPVassociated head and neck squamous cell carcinoma. Cancer Res. 2013; 73:1733-1741.

20. Ukpo OC, Thorstad WL, Lewis JS Jr. B7-H1 expression model for immune evasion in human papillomavirus-related oropharyngeal squamous cell carcinoma. Head Neck Pathol. 2013; 7:113-121.

21. De Meulenaere A, Vermassen T, Aspeslagh S, Huvenne W, Van Dorpe J, Ferdinande L, Rottey S. Turning the tide: clinical utility of PD-L1 expression in squamous cell carcinoma of the head and neck. Oral Oncol. 2017; 70:34-42.

22. Pardoll DM. The blockade of immune checkpoints in cancer immunotherapy. Nat Rev Cancer. 2012; 12:252-264.

23. Taube JM, Anders RA, Young GD, Xu H, Sharma R, McMiller TL, Chen S, Klein AP, Pardoll DM, Topalian SL, Chen L. Colocalization of inflammatory response with B7-h1 expression in human melanocytic lesions supports an adaptive resistance mechanism of immune escape. Sci Transl Med. 2012; 4:127ra137.

24. Tumeh PC, Harview CL, Yearley JH, Shintaku IP, Taylor EJ, Robert L, Chmielowski B, Spasic M, Henry G, Ciobanu V, West AN, Carmona M, Kivork C, et al. PD-1 blockade induces responses by inhibiting adaptive immune resistance. Nature. 2014; 515:568-571.

25. Ilie M, Falk AT, Butori C, Chamorey E, Bonnetaud C, Long E, Lassalle S, Zahaf K, Venissac N, Mouroux J, Cohen C, Brambilla E, Marquette $\mathrm{CH}$, et al. PD-L1 expression in basaloid squamous cell lung carcinoma: Relationship to PD-1+ and CD8+ tumor-infiltrating T cells and outcome. Mod Pathol. 2016; 29:1552-1564.

26. Ratcliffe MJ, Sharpe A, Midha A, Barker C, Scott M, Scorer P, Al-Masri H, Rebelatto M, Walker J. Agreement between Programmed Cell Death Ligand-1 Diagnostic Assays across Multiple Protein Expression Cut-Offs in Non-Small Cell Lung Cancer. Clin Cancer Res. 2017. https://doi.org/ 10.1158/1078-0432.CCR-16-2375.

27. Pai SI, Westra WH. Molecular pathology of head and neck cancer: implications for diagnosis, prognosis, and treatment. Annu Rev Pathol. 2009; 4:49-70.

28. Loyo M, Li RJ, Bettegowda C, Pickering CR, Frederick MJ, Myers JN, Agrawal N. Lessons learned from nextgeneration sequencing in head and neck cancer. Head Neck. 2013; 35:454-463.

29. De Meulenaere A, Vermassen T, Aspeslagh S, Zwaenepoel K, Deron P, Duprez F, Rottey S, Ferdinande L. Prognostic markers in oropharyngeal squamous cell carcinoma: focus on CD70 and tumour infiltrating lymphocytes. Pathology. 2017; 49:397-404. https://doi.org/ 10.1016/j.pathol.2017.02.002.

30. Dahlin AM, Henriksson ML, Van Guelpen B, Stenling R, Oberg A, Rutegard J, Palmqvist R. Colorectal cancer prognosis depends on T-cell infiltration and molecular characteristics of the tumor. Mod Pathol. 2011; 24:671-682.

31. Herbst RS, Soria JC, Kowanetz M, Fine GD, Hamid O, Gordon MS, Sosman JA, McDermott DF, Powderly JD, Gettinger SN, Kohrt HE, Horn L, Lawrence DP, et al. Predictive correlates of response to the anti-PD-L1 antibody MPDL3280A in cancer patients. Nature. 2014; 515:563-567. 